\title{
More people with depression continued treatment with fluoxetine than with desipramine or imipramine
}

Simon GE, Heiligenstein J, Revicki D, et al. Long-term outcomes of initial antidepressant drug choice in a "real world" randomized trial. Arch Fam Med 1999 Jul/Aug;8:319-25.

QUESTION: In patients with depression, does initial treatment with fluoxetine improve clinical, quality of life, and economic outcomes better than desipramine or imipramine?

\section{Design}

Randomised (allocation concealed*), unblinded,* controlled trial with 24 month follow up.

\section{Setting}

Primary care clinics in a health maintenance organisation in Seattle, Washington, USA.

\section{Patients}

536 patients (median age 41 y, 72\% women) who were beginning antidepressant drug treatment. Exclusion criteria were use of antidepressant drugs in the previous 90 days, alcohol abuse, psychotic symptoms, history of mania, recent use of lithium or antipsychotics, or contraindication to the study drug. Follow up was $81 \%$ at 12 months and $72 \%$ at 24 months.

\section{Intervention}

Patients were allocated to ffluoxetine $(n=173)$, desipramine $(n=181)$, or imipramine $(n=182)\} \uparrow$.

\section{Main outcome measures.}

Continuing use of initial medication; remission of depression; change in Hamilton Depression Rating Scale (HDRS) score, Hopkins Symptom Checklist (HSCL) depression subscale score, and SF-36 Mental Component Summary (MCS) score; and cost.

\section{Main results}

Patients who were allocated to fluoxetine were more likely to continue their original medication than were patients who received desipramine $(p<0.001)$ or imipramine $(\mathrm{p}<0.001)$ (table). The likelihood of continuing any antidepressant drug decreased over time and was not affected by initial allocation $(\mathrm{p}=0.95)$ (table). Groups did not differ in the proportion of patients with remission from depression or change in HDRS, HSCL, or SF-36 MCS scores. Drug costs were US $\$ 250$ more over 2 years in the fluoxetine group, but total cost of care did not differ between groups.

\section{Conclusions}

Patients who began antidepressant treatment with fluoxetine were more likely to continue taking it but not more likely to continue taking any antidepressant medication. Clinical and quality of life outcomes improved within 6 months of treatment and did not differ among the fluoxetine, desipramine, and imipramine groups.

*See glossary.

†Simon GE, VonKorff M, Heiligenstein JH, et al. JAMA. 1996;275:1897-902.

\section{COMMENTARY}

This "real life" study by Simon and colleagues gives us insight into how antidepressants are used in practice and the associated costs. Randomised controlled trials with economic modelling tell us a limited amount about the real world. We know that newer drugs cost more, but we do not know how their putative benefits translate into outcome or cost effectiveness.

In this study, the lower rate of switching because of adverse effects suggests that fluoxetine was better tolerated than tricyclics; outcome and willingness to continue taking antidepressants, however, was not affected. The human cost of this difference is difficult to know. Starting treatment with fluoxetine led to greater drug costs than with tricyclics, but switching between antidepressants reduced this difference. The increase in the acquisition costs of fluoxetine may have been balanced by lower medical costs, although the study had limited power to estimate these costs precisely Therefore, the study could not detect a difference in total medical costs of about the same amount as the difference in drug prescription costs. Although we can be fairly confident that first line fluoxetine led to a larger drug bill, we are less certain about how overall costs compared between groups. Even if the costs balance, interpretation depends on which budget you control and on your health care system. The situation is further complicated because we cannot assume that results with fluoxetine will be the same with other selective serotonin reuptake inhibitors and new antidepressants.

Was it appropriate to give any antidepressant to many of these patients with mainly mild depression? Below a certain threshold of severity, antidepressants are less likely to be beneficial; ${ }^{1}$ therefore, these patients could have had up to 2 years of unnecessary drug treatment. Targeting more severely ill patients is at least as important as choosing which antidepressant to use.

Ian Anderson, MBBS, MD, MA University of Manchester Manchester, UK

1 Paykel ES, Hollyman JA, Freeling P, et al. Affect Disord 1998;14:83-95.

Patients continuing initial and any antidepressant medication:fluoxetine $(F l u) v$ desipramine (Des) and imipramine (Imi)

\begin{tabular}{|c|c|c|c|c|}
\hline Outcomes at $12 \mathrm{mo}$ & Comparison & $\begin{array}{l}\text { Continuation } \\
\text { rates }\end{array}$ & $\begin{array}{l}\text { RBI } \\
\text { (95\% CI) }\end{array}$ & $\begin{array}{l}\text { NNT } \\
\text { (CI) }\end{array}$ \\
\hline \multirow[t]{3}{*}{ Continuing initial medication } & Flu $v$ Des & $42 \%$ v $20 \%$ & $\begin{array}{l}107 \% \\
\text { (43 to 201) }\end{array}$ & $\begin{array}{l}5 \\
(4 \text { to } 10)\end{array}$ \\
\hline & Flu $v$ Imi & $42 \%$ v $27 \%$ & $\begin{array}{l}56 \% \\
\text { (13 to 117) }\end{array}$ & $\begin{array}{l}7 \\
\text { (4 to } 25)\end{array}$ \\
\hline & & & RBR (CI) & NNH \\
\hline \multirow[t]{2}{*}{ Continuing any medication } & Flu $v$ Des & $51 \% \vee 54 \%$ & $\begin{array}{l}6.8 \% \\
(-16 \text { to } 25)\end{array}$ & $\begin{array}{l}\text { Not } \\
\text { significant }\end{array}$ \\
\hline & Flu $v$ Imi & $51 \% \vee 50 \%$ & $\begin{array}{l}1.4 \% \\
(-28 \text { to } 19)\end{array}$ & $\begin{array}{l}\text { Not } \\
\text { significant }\end{array}$ \\
\hline
\end{tabular}

ҒRBR = relative benefit reduction. Other abbreviations defined in glossary; RBI, RBR, NNT, NNH, and Cl calculated from data supplied by author.
Source of funding: Lilly Research Laboratories.

For correspondence: Dr G E Simon, Center for Health Studies, Group Health

Cooperative, 1730

Minor Avenue, Suite 1600, Seattle, WA 98101-1448, USA

Fax +1206287 2871 .

A modified version of the abstract and commentary also appears in EvidenceBased Mental Health. 